\title{
El Artis historicae Penus de J. Wolf y P. Perna (1579): reflexiones sobre el arte de leer y escribir historias en el tardo-Renacimiento europeo
}

\section{The Artis historicae Penus of J. Wolf and Pietro Perna (1579): observations on the art of reading and writing histories in late European Renaissance}

\author{
Silvina Paula Vidal \\ silvidal76@gmail.com \\ Doctora y Profesora en Historia \\ Universidad Nacional de San Martín, Escuela de Humanidades \\ Irigoyen, 1650 \\ 1650 - San Martin - Buenos Aires \\ Argentina
}

\begin{abstract}
Resumen
El presente artículo constituye una traducción española con aparato crítico de los prólogos escritos por Johannes Wolf (compilador) y Pietro Perna (tipógrafo) de la primera antología historiográfica del tardo-Renacimiento europeo, denominada Artis historicae Penus (1579); antología que formó parte de un proyecto editorial de nuevo cuño y sin precedentes en lo que respecta a sus propósitos y alcance. En el breve ensayo de presentación que antecede a la traducción se discuten cuatro aspectos relativos a la antología y sus autores: (i.) soportes materiales y paratextuales, (ii.) biográficos, (iii.) político-religiosos y (iv.) gnoseológico-pedagógicos.
\end{abstract}

Palabras clave

Historiografia; Metodologia da história; Renascimento.

\begin{abstract}
This paper is a translation into Spanish, with notes and commentaries, of Artis historicae Penus (Johannes Wolf [compiler] and Pietro Perna [typographer], 1579), the first historiographical anthology of late European Renaissance. This anthology was part of a new unique editorial project regarding its purpose and scope. In the brief presentation essay that precedes the translation, four aspects regarding the anthology and its authors will be addressed: (i) paratextual layout, (ii) biographies, (iii) political and religious contexts, and (iv) epistemological and pedagogical frameworks.
\end{abstract}

Keywords

Historiography; Methodology of history; Renaissance. 


\section{El Artis... como antología histórica: análisis de soportes materiales y paratextuales}

La antología historiográfica de Johannes Wolf y Pietro Perna constituye una de las más conocidas y representativas del género discursivo de las artes historicae en el tardo-Renacimiento europeo. $\mathrm{Y}$ no es para menos: en su versión final de 1579, comprende, en tres tomos, dieciocho preceptivas sobre la escritura y la lectura de textos históricos, entre antiguos y modernos. Se trata de una compilación tan completa que, si bien no presenta reediciones posteriores a 1579 , se conservan en la actualidad varios ejemplares esparcidos en distintas bibliotecas europeas, ${ }^{1}$ además de ser una obra muy citada entre los eruditos del período y los estudiosos de estos temas. En efecto, muchos son los historiadores, desde A. Momigliano (1993, p. 84) hasta A. Grafton (2007, p. 125), que analizaron en detalle las preceptivas contenidas en el Artis...; no obstante, siempre las abordaron como si fueran las fuentes originales, ignorando el hecho de que habían sido sometidas a un doble proceso de des- y recontextualización por parte de los compiladores responsables (Wolf y Perna) en el marco de un proyecto editorial de nuevo cuño y sin precedentes en lo que respecta a sus propósitos y alcance. En un intento por subsanar esa falencia, indagar en las características que asumió el Artis... en tanto proyecto editorial cosmopolita y paralelo a la publicación de artes perigrinandi y de la Biblioteca universalis constituye el objetivo principal de este artículo. Para ello, se atenderá a los cuatro aspectos que, a nuestro criterio, contribuyeron a hacer del Artis... la primera antología renacentista en materia historiográfica: (i) soportes materiales y paratextuales, (ii) biográficos (en relación con los responsables de la compilación), (ii) político-religiosos y (iv) gnoseológico-pedagógicos.

Primeramente, cabe hacer una aclaración: el género discursivo de las artes historicae (cuyo surgimiento es paralelo a las artes poeticae y retoricae), sucesor del estilo libre de las alabanzas a la historia del Quattrocento, expresaba, a mediados del siglo XVI, una obsesión por codificar los modos de leer, comentar y escribir historias (antiguas y modernas) de carácter civil y político (COTRONEO 1971). Asimismo, en ese tipo de producciones se observa una reflexión consciente sobre las prácticas historiográficas del período, vinculadas a una erudición polimática y ecléctica. Aquí se destaca el perfil del intelectual humanista que aspira a reconstruir la Antigüedad (en especial la clásica, pero no exclusivamente) en su conjunto, estableciendo cruces entre la historia civil y diversos campos del conocimiento: desde la historia natural, la medicina y el anticuariado, la cosmografía y la cronología hasta la filología, la crítica literaria y la poesía (GRAFTON 2005). Las preceptivas modernas y las traducciones latinas comentadas de autores antiguos (Dionisio Halicarnaso sobre Tucídides por A. Dudith; Luciano de Samosata por J. Moltzer; y Polibio por A. Foglietta)

\footnotetext{
1 En diversas bibliotecas alemanas (Baviera, Berlín, Gotinga, Wolfenbüttel, etc.); británicas (Londres, Cambridge, Oxford, Escocia); francesas (París, Estrasburgo, Lyon, Poitiers); holandesas (Utrecht, Nimega); italianas (Génova, Roma, Nápoles, Pisa y Venecia), suizas (Basilea, Zurich), españolas (Madrid, Salamanca) y polacas (Varsovia), por mencionar sólo algunas. Nos hemos servido de las dos ediciones de 1579 del Artis historicae Penus, editadas por Perna en Basilea, que se encuentran en la biblioteca del Instituto Warburg y en la British Library de Londres (Inglaterra).
} 
compiladas en el Artis... constituyen un claro ejemplo de esos cruces al servicio de una historia íntegra, atenta a reunir y articular toda pieza de información disponible para lograr una reconstrucción más completa y acabada del pasado (HUPPERT 1970; KELLEY 1998; GRAFTON 2007).

Un análisis del soporte material del Artis..., cuyo formato de edición es in quarto (lo cual indica que se trata de un libro diseñado para una lectura silenciosa y detenida en el estudio), nos presenta un tratado monológico que comunica un discurso cerrado, cuya selección de autores y obras a imitar en materia historiográfica se considera canónica (VIDAL 2016, p. 274). Las portadas de las preceptivas compiladas han sido suprimidas y reemplazadas por una portada acompañada por el logo tipográfico de su editor, Pietro Perna. Y lo mismo se comprueba en las dedicatorias (con excepción de la del Methodus de Bodin), ${ }^{2}$ conservándose sólo los prólogos originales de las preceptivas, donde se alaban las artes historicae como género discursivo. Asimismo, las dedicatorias han sido reemplazadas por otras dos, a cargo del autor (J. Wolf, dirigida a Federico I, príncipe de Wurtemberg) y del editor (P. Perna, dirigida al "amante de historias"). ${ }^{3}$ A las dedicatorias sigue un índice de las dieciocho preceptivas compiladas. Aquí se advierte una repaginación continua de las preceptivas con el propósito no sólo de englobarlas en un mismo tratado, sino también de proporcionar unidad y coherencia a la obra; coherencia y unidad que son reforzadas mediante índices analíticos que se ubican al final de cada tomo, cuya función consiste en detallar y destacar los argumentos y los nombres más notables de cada volumen. A estos indicadores paratextuales que guían y pautan la lectura, se suman marginalias laterales con anotaciones que subrayan los que se consideran nudos argumentales de ciertos autores como Robortello, Bodin, Patrizi, Fox Morcillo y Viperano, entre otros.

La edición de 1579 del Artis... se presenta más claramente como una antología que la de 1576, titulada Joannis Bodinis Methodus histórica. En la edición de 1576, el Methodus de Bodin ocupa un lugar privilegiado, convirtiendo al resto de las preceptivas históricas en agregados o comentarios de esa primera preceptiva, que se toma como modelo. En cambio, en la edición de 1579, si bien el texto de Bodin sigue encabezando la compilación, se produce un cambio de título: Artis historicae Penus (Tesoro del arte histórica), en consonancia con la caracterización que Wolf hace de la obra en su prólogo como "clave de todas las historias" (WOLF 1579, n.p.), aludiendo así, a una concepción totalizante y universal de la memoria histórica de cuyo análisis nos ocuparemos después. Además, se establece una paridad entre escritores antiguos y modernos y se agregan otros cinco autores (C. Mylaeus, C. Pezel, J. Zwinger, J. Sambucus en los dos tomos existentes y A. Riccoboni en un tercero), ${ }^{4}$ brindando de este modo un arco más completo y acabado de las artes historicae del período.

\footnotetext{
2 Más adelante volveremos sobre este punto.

3 Las dedicatorias de Wolf y Perna, que aparecen conjuntamente publicadas en el volumen I de la edición de 1579 del Artis historicae Penus, han sido traducidas y comentadas por primera vez en lengua española por nosotros. Desconocemos que haya, hasta el momento, alguna otra traducción en lengua vernácula.

${ }^{4}$ Con excepción de la edición de 1579 consultada en la Biblioteca del Warburg Institute, donde el texto de Riccoboni se encuentra incluido en el segundo tomo. Una lista cronológica detallada de las preceptivas que se encuentran compiladas en el Methodus Bodini Historica y el Artis historicae Penus puede verse en Witschi-Bernz 1972.
} 


\section{Los responsables del Artis historicae Penus: autoría y edición}

El autor de la compilación, Johannes Wolf (1537-1600), era natural de Bergzabern, región del Palatinado. De familia acomodada, su padre había sido concejal de la ciudad. Wolf tuvo la posibilidad de acceder a una muy buena educación: realizó sus primeros estudios en Estrasburgo, bajo la égida de Johannes Strum. Luego se formó en Teología y Filosofía en las universidades de Wittemberg y Tubinga, tomando contacto con los círculos luteranos de Melanchthon y Jakob Schegk. Y finalmente, tras pasar un tiempo en las ciudades francesas de Bourges y Angers, se doctoró en Derecho Civil y Canónico en 1568 en la Universidad de Dole. Aquí se vinculó, como en su momento lo hiciera Jean Bodin, con Jacques Cujas y la nueva escuela de derecho gálico, que se proponía recuperar el derecho romano deshaciéndose de los prejuicios de los comentaristas medievales y consideraba fundamental reconstruir el pensamiento de los juristas en relación con su época y escuela de pertinencia, evitando así caer en el vicio de aplicar leyes antiguas a contextos nuevos que poco tenían que ver con éstas. No es casual que, en el Artis..., Wolf se refiera a la historia como "filología histórica" (WOLF 1579, f. 2), ligando la disciplina con la recuperación del sentido original de los documentos.

Wolf realizó una importante carrera política: fue abogado de la corte imperial de Espira (ciudad libre del Palatinado); sirvió como diplomático al conde palatino Wolfgang de Pfalz-Zweibrucken ante Catalina de Médicis, Isabel I de Inglaterra y Gaspar de Coligny, para ayudar a los hugonotes franceses con 6.000 soldados de caballería y 16.000 de infantería, durante la tercera guerra de religión (MALISCH 2006; MELCHIOR 1620, p. 341-347); y fue consejero de Philipp Ludwig, duque del Palatinado-Neoburgo, y de Karl II von Baden-Durlach, marqués de Baden-Durlach, quien le confió la administración de Mundelsheim y de la gobernación de Baden (IRTENKAUF 1975).

Habiendo sido testigo privilegiado de la fragmentación geográfica, política y religiosa del Sacro Imperio Romano Germánico y de la inoperatividad al momento de tomar decisiones debido a la dificultad de lograr un acuerdo entre los electores, los colegios de príncipes y las ciudades; Wolf dedicó el Artis... a Federico I de Wurtemberg, príncipe de uno de los estados electores más compactos del imperio (PARKER 2006, p. 10), esperando que éste, a quien definía como un príncipe enérgico, llevara a cabo la unión del imperio frente a amenazas externas poderosas como la representada por los turcos, calificados de "bárbaros" y "enemigos públicos de la Germania" (WOLF 1579, f. 4v-5). Ante la avanzada de la Contrarreforma católica en el Imperio, la lucha con los Habsburgo y los desacuerdos al interior del protestantismo, Wolf se presentaba como un protestante moderado, capaz de ayudar a limar los fanatismos religiosos a favor de la conservación y la integridad del cuerpo político, es decir, de su querida Germania.

Pero hay más: Wolf no sólo se desempeñó como funcionario, abogado y diplomático, sino que además fue traductor (en especial del francés), compilador y editor de tres crónicas históricas (ROLLWAGEN 1601): de A. Kranz, su Crónica de los reinos del norte... y Metrópolis o Historia de la Iglesia bajo Carlomagno en 
Sajonia; y de R. Gauguin, el Compendio sobre los orígenes y los hechos de los francos. ${ }^{5}$ También fue autor de los XVI Centenarios de lecciones memorables, ${ }^{6}$ que, publicadas el año de su muerte, constituyen una miscelánea de profecías sobre Lutero que anunciaban la Reforma protestante. Aquí se advierte una mezcla de enciclopedismo, cronología y crónica de prodigios con la prédica a favor de la religión reformada (VEGA RAMOS, 1994); se trata de un texto que sorprende si lo comparamos con la producción anterior del autor.

El segundo responsable de la compilación, el editor y tipógrafo Pietro Perna, presentaba un derrotero en muchos puntos similar al de Wolf. Originario de la ciudad de Lucca, en el centro-norte de Italia y tipógrafo de profesión, Pietro Perna (1520-1582) se convirtió al protestantismo de la mano de Pietro Martire Vermigli. Esa situación lo obligó a exiliarse y buscar refugio primero en Suiza y luego en Basilea, donde fundó su propia imprenta en 1558. A mediados del siglo XVI, Basilea, ciudad libre del Imperio, constituía el corazón de un circuito internacional del libro, forjado por libreros e impresores que habían sabido aprovechar el contacto frecuente tanto con centros católicos y protestantes como con las comunidades de exiliados. Y Perna era uno de ellos. No sólo publicaba textos de protestantes italianos (como Vergerio, Aconcio, Occhino y Sozzini, entre otros), de Plotino y Paracelso, sino también las obras que a su criterio conformaban el tesoro filosófico, histórico y filológico italiano (representado por autores como Petrarca, Guicciardini, Maquiavelo, Giovio y Castelvetro), con el propósito de asegurar su influencia en Europa del Norte (PERINI 2002, p. 213).

Desde el punto de vista religioso, Perna, al igual que Wolf, era un protestante moderado que, siendo muy crítico de la persecución y la condena de Calvino a antitrinitarios y anabaptistas, se identificaba con la línea filosófica y teológica más amplia y tolerante de la Reforma protestante, en sintonía con Sebastián Castillion y Celio Secondo Curione. Baste como prueba de ello un análisis de la iconografía de su sello editorial, que inaugura con la publicación del comentario de Vermigli, su maestro, a la Epístola de los Romanos. En dicho sello aparece representada una mujer con una linterna en la mano y alrededor de la imagen se lee: "Lucerna pedibus meis verbum tuum" (Tus palabras son la llama que guía mis pasos, salmo 118, línea 105), frase que refiere a una tradición herética italiana que, lejos de concebir la fe como ciega, en el sentido de la predestinación calvinista, la consideraba como iluminación divina cuya tarea consistía en activar el intelecto del hombre (PERINI 2002, p. 221; VIDAL 2016, p. 274).

Si se observa el origen y la confesión religiosa de los autores que integran la antología del Artis..., se advierte la tolerancia y el pluralismo que guiaron a Wolf y Perna al momento de conformar un elenco tan variado y rico. Si bien se trata de autores europeos, provienen de distintas partes de Europa: norte, central

5 KRANZ, A. (1575) Regnorum Aquilonarum Chronica, Frankfurt, Wechel,; KRANZ, A. (1576), Rerum Germanicarum Historici Clarissimi, Ecclesiastica Historia, Sive Metropolis, Frankfurt, Wechel; GAUGIN (1577). Rerum Gallicarum Annales... Frankfurt, Wechel.

${ }^{6}$ WOLF, J. (1600). Lectionum memorabilium et reconditarum centenarii XVI... Lavingae, Rheinmichel. 
y meridional, oriental y occidental: tres griegos (Luciano, Tucídides y Polibio), ${ }^{7}$ siete humanistas italianos (F. Patrizi, G. Pontano, A. Viperano, F. Robortello, U. Foglietta, C. Secondo Curione y A. Ricobboni); cuatro alemanes (J. Moltzer, D. Chytraeus, C. Pezel y S. Grynaeus), dos húngaros (A. Dudith y J. Sambucus), dos suizos (T. Zwinger y J. Stupanus) y un español (S. Fox Morcillo). El pluralismo con pretensiones cosmopolitas de la compilación se ve reforzado, además, por la elección del lenguaje internacional de la época: el latín, lo que implicaba una selección previa de las traducciones latinas de preceptivas que originalmente se habían escrito en otra lengua (como griego o italiano).

\section{La defensa de la historia como modo de conocimiento válido}

En este marco, cabe preguntarse por el contexto cultural en el que surge una antología histórica como el Artis... La palabra "método", que se repite al menos tres veces en los prólogos aquí traducidos, nos brinda una pista. En la segunda mitad del siglo XVI, tuvo lugar un proceso de redescubrimiento del escepticismo antiguo en tanto antecedente del pirronismo histórico, es decir, de la pregunta por los alcances y los límites del conocimiento histórico (GINZBURG 2006, p. 25; FLORIDI 2010, p. 267-287). ${ }^{8}$ Ese tipo de escepticismo se hallaba estrechamente ligado a las traducciones y a las ediciones comentadas de Sexto Empírico producidas entre mediados del siglo XVI y las primeras décadas del siglo XVII: los Esbozos pirrónicos, por Henri Estienne (1562), la publicación conjunta de los Esbozos y la traducción latina de Contra profesores, por Gentien Hervet (1569), y una edición griega anotada integral de ambos textos por los hermanos Petrus y Jacobus Chouet (1621). Con relación a los alcances del conocimiento histórico, una serie de pasajes del libro I (1.248.2 a 1.260.4) de Contra profesores, ya advertidos por Robortello en su De historica facultate disputatio (1548), revistieron particular interés (GINZBURG 2006; VIDAL 2016, p. 70-78). Allí se definía la historia (considerada por Sexto parte de la gramática) como "carente de método", por dos motivos: (i) la infinitud de su materia, la variabilidad constante de los hechos del pasado y la falta de conexión lógica de éstos entre sí; y (ii) la inexistencia de un juicio o criterio para discernir lo verdadero de lo falso.

Frente a las objeciones de Sexto, Wolf y Perna sostienen que el Artis... intenta proveer, a partir de la compilación (o "tesoro") de las preceptivas que lo componen, de un método para la lectura y la escritura de textos históricos, pero ¿cómo debería entenderse la noción de método en ese contexto? Esa noción se inscribe en la defensa de la historia como arte (tékhne) en el sentido de que se le podía aplicar, como a cualquier otra materia del plan de estudios universitario, un método común que consistía en desglosar una serie

\footnotetext{
7 El hecho de que en el índice del Artis figuren comentarios de autores griegos puede dar la falsa impresión de que los latinos han sido excluidos. No obstante, cabe recordar que muchos de los autores romanos que generalmente se comentan en las artes historicae (Cicerón, Salustio, Tito Livio) se encuentran incorporados a las preceptivas de los modernos. Baste recordar que Perna dedica un tercer volumen del Artis al Historia Liber de A. Riccoboni, que comenta una selección de veintidós fragmentos de historiadores y anticuarios romanos, entre quienes se destacan: Salustio, Fabio Píctor, Cornelio Nipote, Varrón, Nigidio y Sereno Sammonico, entre otros.

\& Para otras corrientes escépticas en el período, consúltense Schmitt 1972 y Naya 2009.
} 
de vocablos y argumentos para elaborar una clasificación pormenorizada que facilitara su memorización y comprensión (COUZINET 1996, p. 35-38). Esta técnica pedagógica se asociaba a una concepción universal del saber histórico que, basado en una serie de experiencias comunes, podía ser esquematizado y ordenado por la mente humana para ser almacenado y recuperado cuando se lo considerara necesario. Y era la lógica de ese método de organización de la información lo que aseguraba por sí mismo el acceso a la realidad del pasado y su comprensión. De ese modo, el Artis... se presenta como un cuadro histórico universal que concibe la historia no sólo como una indagación comprensiva (que atraviesa diversas épocas y espacios geográficos), sino también como un instrumento poderoso para clasificar y evaluar los cuantiosos datos disponibles del mundo moderno sobre el pasado (BLAIR 2003; 2004; GRAFTON 2005). No es casual que en la antología ocupen un lugar privilegiado los textos de polímatas anticuarios como Robortello, Patrizi, Balduin, Milieu, Chytraeus y Riccoboni. Asimismo, la palabra "método" y sus derivados ("metódico/a") se encuentra asociada en los prólogos de Wolf y Perna y en los índices analíticos (al final de cada tomo) a la práctica de tomar y organizar notas para sacar lecciones útiles que permitan a los hombres operar en el mundo, tanto en el ámbito privado como público (WOLF 1579, f. 3 y p. 604).

En ese contexto, no es que casual Wolf y Perna hayan elegido el Methodus de Bodin para encabezar la compilación, dejando la dedicatoria del humanista francés a Ravisius Textor, en la cual asociaba la palabra "método" al problema de cómo organizar el material histórico existente y sostenía la existencia de tres etapas en la producción de textos históricos: (i) la recolección de datos; (ii) la organización de éstos; y (iii) la eliminación de errores (que se lograba gracias a una correcta datación cronológica, la comparación de diversas fuentes, el cruce de referencias bibliográficas y la concordancia de autores, entre otros procedimientos). Bodin aconsejaba ordenar el material histórico atendiendo a un razonamiento lógico deductivo: se partía de conceptos generales y definiciones sintéticas para ubicar después (en relación con estas primeras nociones) otras informaciones según su mayor o menor grado de generalidad (REYNOLDS 1969, p. IX-XIII; MCRAE 1955). Una organización similar se advierte en los índices analíticos del Artis..., particularmente en el segundo tomo. Se parte de la definición general de historia como arte y se establece su diferencia con otras artes del discurso (gramática, retórica, poética, filosofía moral). Luego se pregunta por su esencia, en términos aristotélicos, por las formas que adopta: memoria, imágenes, narración. Después se especifica su objeto y se discute la etimología de la palabra. Se arriba a la primera definición sintética: la historia constituye una narración verdadera de los hechos del pasado; y, a partir de allí, se propone una clasificación tripartita: historia natural, humana y divina, de la que derivan distintos tipos de relatos históricos con motivos y finalidades diversas (WOLF 1579, p. 604). Y una misma lógica se aplica a encabezados como "historiador" (historicus) e "historiógrafo" (historiographus), que incluye una sección especial dedicada al método de escritura y elocución de los relatos históricos (WOLF 1579, p. 605). 


\section{Modos de organización y comunicación de saberes, el Artis... y la memoria histórica}

Diversos especialistas (GILBERT 1960; VASOLI 1974; ONG 2004) han insistido en el hecho de que ars, ratio y methodus son términos intercambiables, ya que remiten a una técnica expositiva del discurso que, bajo la influencia de obras como De inventione dialéctica, de R. Agricola (1539), con sus argumentos probables basados en la elaboración de tabula locorum, combinaban lógica y retórica para organizar el dictado de una materia determinada. En el Renacimiento, con la revalorización de la historia civil como tarea cognitiva y política y su incorporación, a través de los studia humanitatis, en la enciclopedia del conocimiento, la obsesión por la búsqueda de un método de enseñanza y de trasmisión del saber histórico se profundiza. Varios son los ensayos que, inspirados en distintas tradiciones, se realizan en ese sentido. La tradición más obvia es la retórica romana (RODRÍGUEZ MAYORGRAS 2004), pero es conveniente recordar que ésta coexiste con tradiciones herméticas y neoplatónicas que, inspiradas en L'idea del Theatro de D. Camillo, el Ars combinatoria de R. Lullio y el de Vita coelitus comparanda de M. Ficino, postulaban que era posible acceder, mediante una serie de signos e imágenes, a una sabiduría oculta capaz de develar el orden último de la realidad (YATES 1974; BOLZONI 1995; 2015).

No obstante, la concepción totalizante de memoria histórica que proponen Wolf y Perna parece inspirada más bien en la reforma pedagógica de Pietro Ramus. En la última mitad del siglo XVI y principios del XVII, las discusiones sobre el arte de la memoria, lejos de restringirse a la magia y el hermetismo, se abren a un contexto intelectual más amplio, relacionado con la búsqueda de métodos de invención y comunicación del conocimiento (BOLZONI 1995; ROSSI, 1989). El proceso coincide con la importancia creciente que cobran la distinción entre dialéctica y retórica, los temas abordados por las disputas lógicas y los avances en matemática y geometría. En este marco, Petrus Ramus (1515-1572), rebelándose contra el milieu universitario parisino, señalaba que la doctrina aristotélica se había corrompido a causa de la confusión terminológica de los comentaristas escolásticos y la contaminación con la teoría retórica tradicional, derivada de Quintiliano. Por ende, para recuperar las verdades presentes en los textos aristotélicos, era vital, según Ramus, poder distinguir claramente la gramática de la dialéctica y la retórica: mientras la gramática se ocupaba de problemas etimológicos, la retórica lo hacía de la invención y el juicio (inventio y dispositio) y la tercera se circunscribía al manejo de técnicas estilísticas y comunicacionales (elocutio, pronunciato, actio), esto es, a la transmisión de los contenidos producidos por la dialéctica. La memoria se convertía así en un instrumento propio de la dialéctica que, unida al orden propio de las cosas y a experiencias comunes, brindaba una interpretación verdadera de la realidad. El programa pedagógico ramista consistía, entonces, en sistematizar y memorizar verbatim los contenidos de las materias del currículum universitario mediante epítomes (exposiciones diagramáticas) que, dispuestos visualmente en la página impresa, partían de aspectos generales de la materia a enseñar y descendían, a través de clasificaciones dicotómicas, a rasgos más específicos o singulares 
(ROSSI 1989, p. 128-133; ONG 2004, p. 95-130). Como sostiene F. Yates (1974, p. 311-34), el método ramista constituye una reelaboración y una crítica del arte clásico de la memoria, porque, a pesar de conservar el principio de orden, suprime tanto el aspecto artificial (las imágenes percusivas y estimulantes) que hacía de la imaginación el instrumento capital de la memoria, como sus aplicaciones mágico-ocultistas, al vincular la memoria casi exclusivamente con los procesos lógicos del intelecto. Esto coincide con la confianza que Wolf y Perna depositaban en un método único para el estudio de la historia, capaz de asegurar por sí mismo el acceso al pasado y su comprensión. Esta cuestión resulta aún más clara si se advierte la supresión intencional de aspectos mágico-herméticos que sufren ciertos textos incorporados al Artis..., como los Diálogos de Patrizi en la traducción latina de Stepanus, a favor de otros más lógicos y susceptibles de sistematización (VIDAL 2016, p. 283-291). Asimismo se advierte una clara asociación entre memoria, lógica, método y gusto por el enciclopedismo, con el propósito de simplificar y transmitir cualquier área del saber con vistas a asegurar un aprendizaje práctico que posibilitara al hombre la manipulación y el control efectivo de su entorno.

No es casual que Perna publicara un año antes de su Methodus historica (la primera versión del Artis..., en 1576) las Praelectiones in Ciceronis de Ramus y las Obras completas de Omer Talon, uno de los discípulos más conocidos de Ramus, e incluya, además en el Artis... dos obras de clara inspiración ramista, como el Methodus de Bodin y el Theatrum Vitae Humanae de Theodor Zwinger

180 (uno abriendo el primer volumen y el otro prácticamente cerrando el segundo).

\section{Prudencia y maquiavelismo}

A las dos acepciones de la palabra "método", relativas a la lectura y a la escritura de textos históricos, se agrega una tercera acepción que, en Wolf y Perna, se vincula con la idea de historia como prudencia. No obstante, la prudencia no es entendida tanto desde el punto de vista ético, como virtud, sino más bien, desde una perspectiva instrumental, como lógica de acción dirigida a la construcción de una ciencia del comportamiento humano. Acá la inclusión del Theatrum de Zwinger en el Artis... cumple un papel fundamental, ya que constituía en ese sentido técnico una de las enciclopedias más exhaustivas de ejemplos (BLAIR 2005, p. 269-296).

En la concepción de historia como prudencia de Wolf se advierte la coexistencia de dos tradiciones que parecerían complementarse: una clásica, que se remonta a Cicerón y se continúa en el Medioevo con Dante Alighieri y en la primera Modernidad, desde el punto de vista iconográfico, con la Alegoría de la prudencia de Tiziano (1565) y los Icones Symbolicae de C. Giarda (1625); y otra técnica (cuyo origen más reciente se sitúa en Maquiavelo y Guicciardini). En su prólogo, Wolf (1579, f. 2v-3r) define la historia como "la memoria de las cosas antiguas, aplicada razonadamente a las coyunturas del futuro". La historia como prudencia conjuga, así, la memoria (de lo que sucedió), la inteligencia (discernimiento de lo que sucede en el presente) y la previsión (en relación con el futuro). De ello resulta que el conocimiento de los hechos del pasado 
permite al hombre obrar juiciosamente en los ámbitos privado y público. En ese marco, Wolf insta a los gobernantes de Germania a seguir el ejemplo histórico de los atenienses para unirse y recaudar fondos y armar un ejército que pueda hacer frente a los turcos con el propósito de asegurar la integridad del imperio. Por ende, el fin último de esta acepción técnica de prudencia (BORRELLI 1994) reside en la conservación del cuerpo político. De ese modo, la adopción de una perspectiva temporal cíclica (que implica una semejanza estructural entre pasado y presente) unida a la dilatación del presente como espacio de experimentación (KOSELLECK 1993; BORRELLI 1993) habilita el cálculo y la codificación de experiencias (pasadas y recientes) para asegurar la pervivencia del orden político.

Ahora bien, si la política ya no se asocia a la ética, ¿qué define a un buen gobernante? Aquí Wolf elogia la capacidad camaleónica (o flexibilidad moral) del hombre político para acomodarse a las circunstancias apelando a diversas estrategias. En ese sentido, la lectura de historias no debe proveer tanto de ejemplos moralmente edificantes, sino "de engaños, ardides, fraudes, supercherías, astucias, trampas, imposturas, calumnias, maldades, crímenes y estratagemas" (WOLF 1579, f. 3r). Apoyándose en la herencia del Renacimiento florentino y muy posiblemente en la lectura que de éste hace Bodin en su Methodus, Wolf adopta una concepción inmanente, materialista y pragmática de la historia secular (civil y política) en la que no interesan los imperativos éticos, sino la capacidad de acción real y efectiva en el presente. Baste señalar dos ejemplos presentes en su dedicatoria a Federico I de Wurtemberg:

La referencia al pasaje de las Vidas Paralelas de Plutarco en el cual Lisandro afirma que "si no alcanza la fuerza de Heracles", había que "usar la astucia de la zorra" (WOLF 1579, f. 3r-v). Aquí se alude al cap. XVIII de El príncipe, donde Maquiavelo aconseja al hombre político servirse correctamente de "la bestia", es decir, aprender a adoptar la piel de león "para amedrentar a los lobos" y la de zorra, "para conocer las trampas" (MAQUIAVELO 1999, p. 103-104).

La recomendación de imitar la astucia del cangrejo, que, no pudiendo capturar a las ostras por la fuerza (porque su caparazón es impenetrable), espera, para hacerlo con éxito, a que "se abran para tomar la luz del sol", volviéndose así "visibles" (WOLF 1579, f. 3v). Nuevamente, en el arte de gobernarse a sí mismo y al cuerpo político, el recurso a la violencia siempre debe saber sopesarse con el recurso a la astucia y la sagacidad.

Perna no podía acordar más con las referencias oblicuas de Wolf a Maquiavelo. Su simpatía por el canciller florentino nacía de la asociación que los refugiados italianos establecían entre la reforma de la Iglesia (entendida como iglesia espiritual) y los ideales de libertad política, régimen republicano y anticlericalismo que impulsaba Maquiavelo, quien además responsabilizaba a la Iglesia romana por la crisis política y moral de Italia (GRANADA 1998). Perna conjugaba esa crítica con la censura a las prácticas represivas del calvinismo contra antitrinitarios y anabaptistas, similares a las aplicadas por la Iglesia romana. En 1560, Perna publica la primera traducción latina de El príncipe, 
realizada por Silvestro Tegli, en cuyo prólogo condena la primacía política que buscaba el calvinismo mediante la destrucción de las instituciones existentes (PERINI 2002, p. 170-192).

No obstante, si en 1560 la referencia a Maquiavelo era explícita, ¿por qué se vuelve oblicua dieciséis años después? En marzo de 1576, meses antes de que Wolf terminara su dedicatoria de Methodus histórica (fechada en agosto de ese año), Innocent Gentillet (un hugonote que había logrado escapar a la matanza de San Bartolomé) publicaba su Discurso contra Maquiavelo. La oleada de antimaquiavelismo comenzaba a cobrar fuerza en Europa. Los italianos aparecían como maestros de la corrupción moral y política, ateos y principales responsables de las guerras de religión francesas. En Ginebra y Basilea, Gentillet había tenido una recepción favorable entre los calvinistas que sospechaban del nicomedismo y del antitrinitarismo de los refugiados italianos (STEWARD 1969; ANGLO 2005, p. 271-373). Frente a una recepción adversa, es muy probable que, con sus referencias indirectas a Maquiavelo vía Plutarco y la metáfora del cangrejo, Wolf y Perna buscaran evitar la censura del Artis...

\section{Conclusiones}

Más allá de su carácter de preceptiva canónica (esto es, de selección de determinados autores y textos a imitar en la escritura de textos históricos), estudiar fuentes como el Artis... implica acercarse a la reflexión consciente en torno a las prácticas historiográficas del período (siempre en diálogo con diversos saberes y prácticas de erudición), así como preguntarse por la naturaleza y los alcances del conocimiento histórico. Hemos intentado demostrar que el Artis..., lejos de ser una compilación guiada por preferencias estilísticas y la repetición de topoi retóricos atemporales (relativos a la historia como "maestra de vida", "filosofía en ejemplos", "luz de la verdad", etc.), constituyó un proyecto editorial con un anclaje concreto en determinado contexto político y religioso: el avance del calvinismo, los fanatismos religiosos y los conflictos al interior del Sacro Imperio Romano Germánico, cuya integridad y estabilidad se hallaba comprometida ante la amenaza turca y las rivalidades internas políticas y confesionales. En ese contexto difícil, una lectura comprensiva de textos históricos que alentara la reflexión sobre cómo construir un orden político estable y tolerante se volvía insoslayable. El Artis... cumplió así un papel no menor en la defensa de la historia como modo de conocimiento válido contra el escepticismo antiguo, al insistir, por un lado, en el carácter metódico de la disciplina (en las tres acepciones que vimos) y, por otro, en una concepción integral de historia que apelaba al uso de toda evidencia material disponible para la reconstrucción de la Antigüedad en su conjunto, excediendo al documento escrito y vinculándose con las prácticas del anticuariado.

\section{Referencias bibliográficas}

ANGLO, Sydney. Machiavelli. The First Century. Studies in Enthusiasm, Hostility, and Irrelevance. Oxford: Oxford University Press, 2005. 
BLAIR, Anne. Reading Strategies for Coping Information Overload ca. 15501700. Journal of the History of Ideas, v. 64, n. 1, p. 11-28, 2003.

. Note Taking as an Art of Transmission. Critical Inquiry, n. 31, p. 85107, 2004.

. Historia in Theodor Zwinger's Theatrum humanae vitae. In: POMATA, Gina; SIRIASI, Nancy (Ed.) Historia: Empiricism and Erudition in Early Modern Europe. Cambridge-Mass.: MIT Press, 2005, p. 269-296.

BOLZONI, Lina. La stanza della memoria: modelli letterari e iconografici dell'età della stampa. Turín: Einaudi, 1995.

BOLZONI, Lina. Camillo, L'idea del theatro con L'idea dell'eloquenza, il De Transmutatione e altri testi inediti. Milán: Adelphi, 2015.

BORRELLI, Giancarlo. Ragion di stato: I'arte italiana della prudenza política. Nápoles: Istituto Italiano per gli Studi Filosofici, Archivo della Ragion di Stato, 1994.

Ragion di stato e leviatano: conservazione e scambio alle origini della modernità política. Bolonia: Il Mulino, 1993.

COUZINET, Marie Dominique. Histoire et méthode à la Renaissance. Une lecture del Methodus de Jean Bodin. París: Vrin, 1996.

COTRONEO, Girolamo. I trattatisti dell'ars historica. Nápoles: Giannini, 1971.

FLORIDI, Luciano. Sextus Empiricus: the transmission and recovery of pyrrhonism. New York; Oxford: Oxford University Press, 2010.

GILBERT, Neal. Renaissance Concepts of method. New York-Cambridge: Cambridge University Press, 1960.

GINZBURG, Carlo. Il filo e le tracce. Vero falso finto. Milán: Feltrinelli, 2006.

GRAFTON, Anthony. The Identities of History in Early Modern Europe: Prelude to a Study of the Artes Historicae. In: POMATA, Gina; SIRAISI, Nancy. Historia: empiricism and erudition in early modern Europe. Cambridge: MIT Press, 2005, p. 41-74.

What was history? The Art of History in Early Modern Europe. Cambridge: Cambridge University Press, 2007.

GRANADA, Miguel Ángel. Maquiavelo y Giordano Bruno: religión civil y crítica del cristianismo. Bruniana \& Campanelliana, v. IV, n. 2, p. 343-368, 1998.

HUPPERT, George. The idea of perfect history: historical erudition and historical philosophy in Renaissance France. Urbana: University of Illinois Press, 1970.

IRTENKAUF, Wolfgang. Johann Wolff, Amtmann zu Mundelsheim. Ludwigsburger Geschichtsblätter, n. 27, p. 89-116, 1975.

KELLEY, Donald. Faces of history: historical inquiry from Herodotus to Herder. New Haven-Connecticut: Yale University Press, 1998. 
KOSELLECK, Reinhart. Futuro-Pasado. Barcelona: Paidós Ibérica, 1993.

MALISCH, Kurt. Le comte palatin Wolfgang de Deux-Ponts et Neubourg et les huguenots français. Société Montgelas pour la promotion de la coopération franco-bavaroise (Ass. Loi 1901). München; Paris, 2006. Disponible dans: <http://www.bayern-france.info/pdf/Kapitel_3_ Beitrag_1_neu.pdf>. Accès à: 9 déc. 2016.

MAQUIAVELO, Nicolás. El príncipe. Traducción española de Miguel Ángel Granada. Madrid: Alianza, 1999.

MCRAE, Kenneth. Ramist Tendencies in the Thought of Jean Bodin. Journal of the History of Ideas, v. 16, n. 3, p. 306-323, 1955.

MELCHIOR, Adam. Vitae Germanorum Iureconsultorum et Politicorum... Frankfurt: Hered. J. Rosae. Heidelberg J. Geyder- Acad. Typogr, 1620.

MOMIGLIANO, Arnaldo. Ensayos de historiografía antigua y moderna. México: Fondo de Cultura Económica, 1993.

NAYA, Emmanuel. Renaissance Pyrrhonism: a relative phenomenon. In: PAGANINI, Gianni; NIETO, José. Renaissance Scepticisms. Springer: Dordrecht, 2009.

ONG, Walter. Ramus, Method and the Decay of Dialogue. From the art of discourse to the art of reason. Chicago; Londres: The University of Chicago Press, 2004.

PERINI, Leandro. La vita e i tempi di Pietro Perna. Roma: Edizioni di Storia e Letteratura, 2002.

REYNOLDS, Beatrice. Method for the Easy Comprehension of History by Jean Bodin. New York: Columbia University Press, 1969.

RODRÍGUEZ MAYORGAS, Ana. El concepto de las artes liberales a fines de la República Romana. Estudios clásicos, t. 46, n. 125, p. 45-64, 2004.

ROLLWAGEN, Gregor. Panegyricus, De vita et obitu Johannis Wolfii IC. De Tabernis Montanis. Tübingen: C. Erhard, 1601.

ROSSI, Paolo. Clavis Universalis. El arte de la memoria y la lógica combinatoria de Lulio a Leibniz. México: Fondo de Cultura Económica, 1989.

SCHMITT, Charles. Cicero Scepticus. A Study of the Influence of the Academica in the Renaissance. La Haya: Martinus Nijhoff, 1972.

STEWARD, Pamela. Innocent Gentillet e la sua polemica antimachiavellica. Florencia: La Nuova Italia, 1969.

VASOLI, Cesare. Profezia e ragione. Studi sulla cultura del Cinquecento e del Seicento. Nápoles: Morano, 1974.

VEGA RAMOS, María. Vaticinia de Adventu Lutheri. La interpretación de textos proféticos y la construcción de la imagen del Reformador. Studia Histórica. Historia Moderna, v. XII, p. 205-233, 1994. 
VIDAL, Silvina. La historiografía italiana en el tardo-Renacimiento. Buenos Aires: Miño y Dávila, 2016.

WITSCHI-BERNZ, Astrid. Main Trends in Historical-Method Literature: Sixteenth to Eighteenth Centuries. History and Theory, v. 12, p. 51-90, 1972.

WOLF, Johannes. Artis historicae penus. Octodecim scriptorum tam veterum quàm recentiorum monumentis $\&$ inter eos Io. praecipuè Bodini libris Methodi historicae sex instructa, Basileae: ex officina Petri Pernae, v. 1, 1579.

YATES, Francis. El arte de la memoria. Madrid: Taurus, 1974. 